\title{
SHORT PAPER
}

\section{Randomised crossover study of the Flutter device and the active cycle of breathing technique in non-cystic fibrosis bronchiectasis}

\author{
C S Thompson, S Harrison, J Ashley, K Day, D L Smith
}

Thorax 2002;57:446-448

See end of article for authors' affiliations

\section{................ \\ Correspondence to:}

Dr C S Thompson,

Department of Medicine, Frenchay Hospital, North Bristol NHS Trust, Bristol

BS16 1LE, UK:

catherine.thompson@shc-tr. swest.nhs.uk

Revised version received 12 November 2001

Accepted for publication 30 November 2001

\begin{abstract}
Background: Airway clearance techniques are an important part of the routine care of patients with bronchiectasis. The use of the Flutter, a hand held pipe-like device causing oscillating positive expiratory pressure within the airways, has been proposed as an alternative to more conventional airway clearance techniques.

Methods: A randomised crossover study was performed in 17 stable patients with non-cystic fibrosis bronchiectasis at home, in which 4 weeks of daily active cycle of breathing technique (ACBT) were compared with 4 weeks of daily physiotherapy with the Flutter device.

Results: No significant differences between the two techniques were found. Median weekly sputum weights were similar with a median treatment difference of $7.64 \mathrm{~g}(p=0.77)$ and there was no evidence of treatment order or order interaction effects $(p=0.70)$. Health status (Chronic Respiratory Disease Questionnaire) and ventilatory function did not change significantly during either treatment period. There was no significant change in peak expiratory flow rate or in breathlessness (Borg score) after individual physiotherapy sessions with either technique. A questionnaire indicated subjectively that patients preferred the Flutter $(11 / 17)$ to $A C B T$ for routine use.
\end{abstract}

Conclusions: Daily use of the Flutter device in the home is as effective as ACBT in patients with noncystic fibrosis bronchiectasis and has a high level of patient acceptability.
A irway clearance techniques such as chest physiotherapy remain an important part of treatment in bronchiectasis, together with prompt antibiotic treatment for infective exacerbations. Interest has been generated in the Flutter device (Varioraw SARL, Scandipharm Inc, Birmingham, Alabama, USA), an alternative to more conventional techniques, which has been tried in a number of respiratory diseases with chronic sputum production including cystic fibrosis (CF), ${ }^{1-6}$ chronic obstructive pulmonary disease (COPD), ${ }^{7-9}$ asthma, $^{10}{ }^{11}$ and diffuse panbronchiolitis. ${ }^{12}$

The Flutter is a simple hand held pipe-like device (fig 1) which produces an oscillating pressure wave through the repeated displacement of a steel ball within a cone. The oscillating positive expiratory pressure is reported to prevent premature closure of the bronchi, to loosen secretions, and allows mobilisation of sputum which may be cleared by the forced expiratory technique (FET).$^{10}$ It is not available on prescription in the UK and costs approximately $£ 45.00$.

The current literature on the efficacy of the Flutter is limited and studies of its use in bronchiectasis have been in patients with CF. A randomised crossover study of patients with stable CF compared 4 weeks of treatment with the Flutter with autogenic drainage. No differences were found in sputum

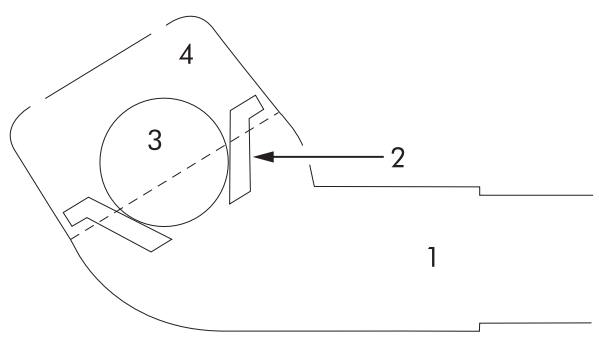

Figure 1 Diagram of the Flutter device and its constituent parts: 1 = mouthpiece, 2 = circular cone, 3 = high density stainless steel ball, 4 = perforated protective cover. weight or lung function after a single session with either method at the end of the treatment period, but sputum viscoelasticity was significantly reduced with the Flutter. ${ }^{13}$ Konstan et al reported that up to three times more sputum was produced with the Flutter than with postural drainage in similar subjects. ${ }^{3}$ In contrast, again in patients with stable CF, Pryor et al found that significantly more sputum was produced with the active cycle of breathing technique (ACBT) than with the Flutter in individual supervised sessions, but similar sputum weights were produced with both methods over 24 hours. ${ }^{1}$ Two studies compared the Flutter with percussion, vibration, and postural drainage by a physiotherapist in children with $\mathrm{CF}$ admitted to hospital with an acute exacerbation and found no significant differences in lung function or exercise tolerance. ${ }^{24}$

Most studies are short with physiotherapist supervision in hospitalised patients. ${ }^{124}$ Comparisons have been made between sputum produced from individual physiotherapy sessions rather than total daily production over several days. ${ }^{13}$ One study of more than a year in children with CF compared the Flutter with the positive expiratory pressure mask and found a greater decline in forced vital capacity (FVC), increased hospital admissions, and increased antibiotic use with the Flutter. ${ }^{6}$

Different airway clearance techniques used for comparison with the Flutter, inconsistencies in its application, and various outcome measures all contribute to the difficulties in interpreting the literature. The physiological properties of sputum differ in CF and non-CF bronchiectasis, ${ }^{14}$ so different airway clearance techniques may vary in their efficacy.

To our knowledge there are no comparative studies with the Flutter device in patients with non-CF bronchiectasis. We have performed a study in such patients at home, comparing the efficacy of the Flutter with ACBT.

\section{METHODS}

\section{Study design}

ACBT and the Flutter were each used unassisted at home for 4 weeks in a randomised crossover design. Patients with productive bronchiectasis attending a specialist respiratory outpatient 
Table 1 Baseline characteristics and treatment differences between 4 weeks of treatment with the Flutter and 4 weeks of ACBT

\begin{tabular}{|c|c|c|c|c|}
\hline \multirow[b]{2}{*}{ Variable } & \multicolumn{2}{|c|}{ Baseline characteristics } & \multirow[b]{2}{*}{ Difference $(95 \% \mathrm{CI})(\mathrm{n}=17)$} & \multirow[b]{2}{*}{$p$ value } \\
\hline & $\begin{array}{l}\text { Flutter first } \\
(n=13)\end{array}$ & $\begin{array}{l}\text { ACBT first } \\
(n=9)\end{array}$ & & \\
\hline Age (years)* & $59(8)$ & $68(16)$ & - & - \\
\hline Sex, male $(\%)$ & $5(38)$ & $3(33)$ & - & - \\
\hline Percentage predicted $\mathrm{FEV}_{1}{ }^{*}$ & $0.67(0.38)$ & $0.70(0.42)$ & - & - \\
\hline Percentage predicted FVC* & $0.73(0.31)$ & $0.83(0.23)$ & - & - \\
\hline Percentage predicted PEFR* & $0.90(0.21)$ & $0.86(0.35)$ & - & - \\
\hline Sputum weight over 4 weeks $(\mathrm{g})$ * & - & - & 7.64 & 0.77 \\
\hline Post bronchodilator FEV (I) & $1.40(1.05)^{*}$ & $1.60(1.05)^{*}$ & $0.08(0.01$ to 0.15$)$ & 0.03 \\
\hline Post bronchodilator FVC (I) & $2.10(1.15)^{*}$ & $2.55(1.00)^{*}$ & $0.11(-0.19$ to 0.24$)$ & 0.09 \\
\hline Post bronchodilator PEFR (I/min) & $350(180)^{*}$ & $340(120)^{*}$ & $7.70(-9.73$ to 25.13$)$ & 0.36 \\
\hline CRQ Total $\ddagger$ & $4.44(0.94)$ & 4.01 (1.19) & $-0.09(-0.37$ to 0.19$)$ & 0.50 \\
\hline CRQ Dyspnoea $\ddagger$ & $3.87(1.15)$ & $3.51(1.28)$ & $0.01(-0.49$ to 0.51$)$ & $>0.99$ \\
\hline$C R Q$ Fatigue $\ddagger$ & $4.25(1.44)$ & $3.44(1.60)$ & $-0.19(-0.82$ to 0.45$)$ & $>0.99$ \\
\hline CRQ Mastery $\ddagger$ & $4.84(0.98)$ & $5.00(1.24)$ & $-0.10(-0.65$ to 0.46$)$ & $>0.99$ \\
\hline CRQ Emotional Function $\ddagger$ & $4.39(0.92)$ & $4.11(1.31)$ & $-0.06(-0.63$ to 0.52$)$ & $>0.99$ \\
\hline $\begin{array}{l}\text { PEFR difference before }- \text { after morning session } \\
(1 / \mathrm{min})^{*} \dagger\end{array}$ & - & - & -2.50 & 0.38 \\
\hline $\begin{array}{l}\text { PEFR difference before - after evening session } \\
\text { (I/min) }\end{array}$ & - & - & $-2.72(-6.95$ to 1.52$)$ & 0.30 \\
\hline Borg difference before - after morning session $\dagger$ & - & - & $0.13(-0.08$ to 0.34$)$ & 0.36 \\
\hline Borg difference before - after evening session* & - & - & -0.04 & $>0.99$ \\
\hline
\end{tabular}

$\mathrm{ACBT}=$ active cycle of breathing technique; $F E V_{1}=$ forced expiratory volume in 1 second; $F V C=$ forced vital capacity; PEFR = peak expiratory flow rate; $C R Q=$ Chronic Respiratory Disease Questionnaire. Values are mean (SD) and mean difference ( $95 \%$ confidence intervals) unless otherwise stated. $p$ values are obtained using the $t$ test for normally distributed data and Wilcoxon rank sum tests otherwise. * Median (IQR) values; †seven in Flutter arm followed by ACBT; łseven in Flutter arm followed by ACBT, eight in ACBT arm followed by Flutter.

clinic were recruited. Baseline medication was not altered. Exclusion criteria were an inability to perform pulmonary function tests, current pneumothorax, untreated cor pulmonale, and haemoptysis. Patients who had had an exacerbation in the 4 weeks prior to or during the study were withdrawn.

All patients had previously been trained in the ACBT (breathing control, thoracic expansion exercises, and FET) and postural drainage. Before the ACBT arm each patient had a refresher session with the physiotherapist $(\mathrm{SH})$ who optimised their technique. Before the Flutter arm they were instructed to tilt the device until maximum vibrations were felt within the chest to loosen the sputum which was cleared with FET. They were asked to perform the airway clearance techniques twice daily until there was no further sputum to expectorate. Written instructions were provided. Postural drainage was used as necessary throughout.

Patients recorded the daily weight of sputum produced (Ohaus LS200 electronic scales), the duration of physiotherapy, peak expiratory flow rate (PEFR), and breathlessness (Borg scale) before and after each physiotherapy session. Post bronchodilator spirometric tests, PEFR, and health related quality of life (Chronic Respiratory Disease Questionnaire (CRQ)) were measured at baseline and after each arm. A questionnaire on completion of the study asked which technique was preferred for routine use.

\section{Statistical analysis}

The study was powered to detect a standardised effect size of 0.8 . Fifteen patients provide $80 \%$ power to detect this using a paired $t$ test with a two sided $5 \%$ significance level. One patient failed to complete their sputum diary for week 4 under both treatments so the mean value for 3 weeks was used. For the Borg scores and PEFR, the mean difference between the values recorded immediately before and after treatment, averaged over each 4 week arm, were used. Normally distributed data are expressed as mean (SD) values and treatment differences with 95\% confidence intervals (CI) were analysed using the $t$ test. Non-normal data are expressed as median values with interquartile range (IRQ) and differences were analysed using the Wilcoxon rank sum test. A change of \pm 0.5 in the CRQ score is associated with a minimum clinically important difference in health status. In addition, for each outcome, tests were performed for a treatment effect, an order effect, and for order interaction. Bonferroni corrections were applied as appropriate. A p value of $<0.05$ was considered statistically significant.

\section{RESULTS}

Five of the 22 patients recruited to the study were withdrawn. All five used the Flutter first; three dropped out because of an infective exacerbation (two during the Flutter arm and one during the ACBT arm) and two recorded insufficient data for analysis. Baseline characteristics for all who entered the study are shown in table 1.

The diagnosis of bronchiectasis had been confirmed by prior CT scanning (14/17) or bronchography (3/17). None had CF; the underlying aetiology of the bronchiectasis was unknown in six cases, post-pneumonic in four, post-whooping cough in six, and one was associated with inflammatory bowel disease.

There was no significant difference between the ACBT and Flutter for any outcome (table 1), nor was there evidence to suggest any treatment order or interaction effect $(p>0.1)$. Median (IQR) daily sputum weights were $26.6 \mathrm{~g}$ (15.0-45.2) for ACBT and $23.4 \mathrm{~g}(16.8-36.2)$ for the Flutter $(\mathrm{p}>0.05)$. There was a statistically significant improvement in $\mathrm{FEV}_{1}$ with the Flutter, but this did not achieve a clinically meaningful change. The mean (SE) total time spent each day performing the airway clearance techniques was similar (29.5 (17.0) minutes and 25.9 (11.7) minutes for the ACBT and Flutter, respectively; $p>0.05$ ). Eleven of the 17 patients preferred the Flutter for routine daily use, three preferred ACBT, and three had no preference. One patient reported nausea using the Flutter; no other adverse events occurred.

\section{DISCUSSION}

This study shows that the Flutter is as effective in aiding sputum clearance in patients with non-CF bronchiectasis as the ACBT. Previous studies have frequently been performed in hospital with supervision from a physiotherapist and over a shorter time varying from a single physiotherapy session ${ }^{13}$ to a few days. ${ }^{14}$ Our study confirms the efficacy of the device when used unsupervised by the patient in the home over a period of 
1 month. Many earlier studies ${ }^{2-5}{ }^{13}$ did not include comparison with the now widely accepted ACBT, nor did they include FET with the Flutter, ${ }^{15}$ and this may explain why we have found the technique to be effective where others have not.'

Ventilatory function, sputum production, and health related quality of life are not the only important outcome measures; exercise capacity, use of medication, the number and duration of infective exacerbations, and cost effectiveness are other parameters not addressed by our study which could be incorporated into a future study over a longer period.

The Flutter was well tolerated; there were no adverse events with either technique, although one patient reported nausea after using the Flutter and a pneumothorax has been reported in the literature in a patient with panbronchiolitis. ${ }^{12}$ Like others, ${ }^{310}{ }^{11}$ we have found the Flutter to have a high level of patient acceptability; 11 of the 17 patients preferred the Flutter for routine use and its ease of use was commented upon.

A recent review of airway clearance techniques in adults ${ }^{15}$ has suggested that, if the objective differences are small between the different techniques, then individual preferences are likely to play an important part in compliance with treatment. We have found the Flutter to be as effective as the ACBT in the home in a group of patients with non-CF bronchiectasis and therefore suggest that individuals with bronchiectasis should be offered a trial of the Flutter and, if preferred by them, it should be recommended for regular daily use.

\section{ACKNOWLEDGEMENTS}

The authors acknowledge the Medical Illustration Department, $\mathrm{K}$ Parry and Dr C Rogers, Research and Development Unit, North Bristol NHS Trust.

\section{Authors' affiliations}

C S Thompson, S Harrison, J Ashley, K Day, D L Smith, Department of Medicine, Frenchay Hospital, Bristol BS16 ILE, UK

Funded by Frenchay Respiratory Research Fund.

Conflict of interest: none.

\section{REFERENCES}

1 Pryor JA, Webber BA, Hodson ME, et al. The Flutter VRP1 valve as an adjunct to chest physiotherapy in cystic fibrosis. Respir Med 1994;88:677-81.

2 Gondor M, Nixon PA, Mutich R, et al. Comparison of Flutter device and chest physical therapy in the treatment of cystic fibrosis pulmonary exacerbation. Pediatr Pulmonol 1999;28:255-60.

3 Konstan MW, Stern RC, Doershuk CF. Efficacy of the Flutter device for airway mucus clearance in patients with cystic fibrosis. J Pediatr 1994; 124:689-93

4 Homnick DN, Anderson K, Marks JH. Comparison of the Flutter device to standard chest physiotherapy in hospitalized patients with cystic fibrosis. A pilot study. Chest 1998;114:993-7.

5 Lindemann $\mathbf{H}$. The value of physical therapy with VRP1-Destin (in German). Pneumologie 1992;46:626-30.

6 Mcllwaine PM, Wong LTK, Peacock D, et al. Long-term comparative tria of positive expiratory pressure versus positive expiratory pressure (flutter) physiotherapy in the treatment of cystic fibrosis. J Pediatr 2001;138:845-50.

7 Bellone A, Lascioli R, Raschi S, et al. Chest physical therapy in patients with an acute excerbation of chronic bronchitis: effectiveness of three methods. Arch Phys Med Rehabil 2000;81:558-60.

8 Ambrosino N, Callgari G, Galloni C, et al. Clinical evaluation of oscillating positive expiratory pressure for enhancing expectoration in diseases other than cystic fibrosis. Monaldi Arch Chest Dis 1995;50:269-75

9 Cegla UH, Retzow A. Physiotherapy with the VRP1 for chronic obstructive pulmonary diseases: results of a multicenter comparative study. Pneumonologie 1993;47:636-9.

10 Girard JP, Terki N. The Flutter VRP1: a new personal pocket therapeutic device used as a adjunct to drug therapy in the management of bronchial asthma. J Invest Allergol Clin Immunol 1994;4:23-7.

11 Swift GL, Rainer T, Saran R, et al. Use of flutter VRP1 in the management of patients with steriod-dependant asthma. Respiration 1994:61:126-9.

12 Burioka N, Sugimoto Y, Suyama H, et al. Clinical efficacy of the Flutter device for airway mucus clearance in patients with diffuse panbronchiolitis. Respirology 1998;3:183-6.

13 Apps EM, Kieselmann R, Reinhardt D, et al. Sputum rheology changes in cystic fibrosis lung disease following two different types of physiotherapy. Flutter vs autogenic drainage. Chest 1998;114:171-7.

14 Wills P, Hall R, Chan W, et al. Sodium chloride increases the transportability of cystic fibrosis and bronchiectasis sputum on mucus-depleted bovine trachea. J Clin Invest 1997:99:9-13.

15 Pryor JA. Physiotherapy for airway clearance in adults. Eur Respir J 1999;14:1418-24. 